\title{
Cosmeceutical role of Medicinal plants / Herbs: A Review on commercially available Cosmetic ingredients
}

Available online at www.jijistweb.com

\section{REVIEW ARTICLE}

\author{
Rahul Kumar Gupta*1, ${ }^{\text {1 }}$ radeep Soni ${ }^{2}$, Jitendra Shrivastava ${ }^{3}$, Pawan Rajput ${ }^{4}$, Shalini Parashar ${ }^{5}$ \\ ${ }^{1}$ Assistant Professor, Dept of Dravyaguna, Govt. Ayurved College, Gwalior, M.P., India. \\ ${ }^{2}$ Assistant Professor, Dept of Rachana Sharir, Govt. Ayurved College, Gwalior, M.P., India. \\ ${ }^{3}$ Assistant Professor, Dept. of Panchakarma, Govt. Ayurved College, Gwalior, M.P., India. \\ ${ }^{4}$ Assistant Professor, Dept. of Rasashastra \& Bhaishajya Kalpana, Govt. Ayurved College, Gwalior, \\ M.P., India. \\ ${ }^{5}$ Assistant Professor, Rog Nidana Evam Vikriti Vijnan, Govt. Ayurved College, Gwalior, M.P., India. \\ *Corresponding Author's E-mail: drrahul786@gmail.com
}

\begin{abstract}
Cosmeceuticals are cosmetic products intended to improve physical appearance, health, beauty and skin ailments. Drugs used to control acne, anti-wrinkle effects, protect from sun burn, improves complexation, delayed effect of ageing and improve skin textures, etc. are comes under category of cosmeceuticals. Cosmeceuticals may be synthetic, natural or hybrid depending upon their compositions. Herbal cosmeceuticals are gaining great attention now a day's due to their wide range of availability and fewer side effects. There are enormous plants and natural ingredients available commercially as cosmeceuticals. Herbal cosmetics originated naturally from plants, sea, rock salt and soil, etc. Generally herbal cosmetics are free from harmful synthetic chemicals and considered safe to use. Many medicinal plants and herbs offers effect like cosmeceuticals and used extensively for same purpose globally. Natural herbs such as; Neem, Kapoor, Henna, Hirda, Behada, Amalaki, Bringaraj, Rosary Pea and Mandor, etc. are used in cosmetic industry for various purpose. This article presented a descriptive review on Herbal cosmeceuticals.
\end{abstract}

Keywords: Ayurveda, Cosmeceuticals, Natural Herbs, Plants, Beauty.

\section{Introduction}

Cosmeceuticals are compounds having medicinal benefits towards the improvement of physical appearance and overall beauty. These are cosmetic products used for beautification as well as for different skin ailments. Commercially they are available as cream, ointments, body lotions, face packs, skin cleansers, fairness formulation, hair shampoo, eye-liner, lipstick, face powder and beauty soap. These products improve functioning/texture of the skin, boost collagen growth, scavenge free radicals, and maintain keratin \& skin healthier (1-5).

Herbal cosmetics are natural products containing pure herbs or permissible cosmetic herbal ingredients in crude or extract form to offer beautification. The requirement of herbal cosmetic is increasing currently due to their compatibility with skin, extensive availability and lack of side effects. Large number of herbs are available commercially as cosmetic for skincare, hair care and antioxidants effects. These herbal formulations when rubbed, poured, sprinkled or sprayed externally or applied to body parts produces cleansing \& beautifying effects, promotes attractiveness and improves overall appearance (6-10).

\section{Some natural plants/herbs/ingredients used in cosmetic industry are as follows:}

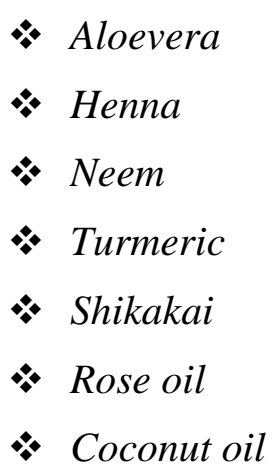


* Sunflower oil

* Olive oil

* Jojoba oil

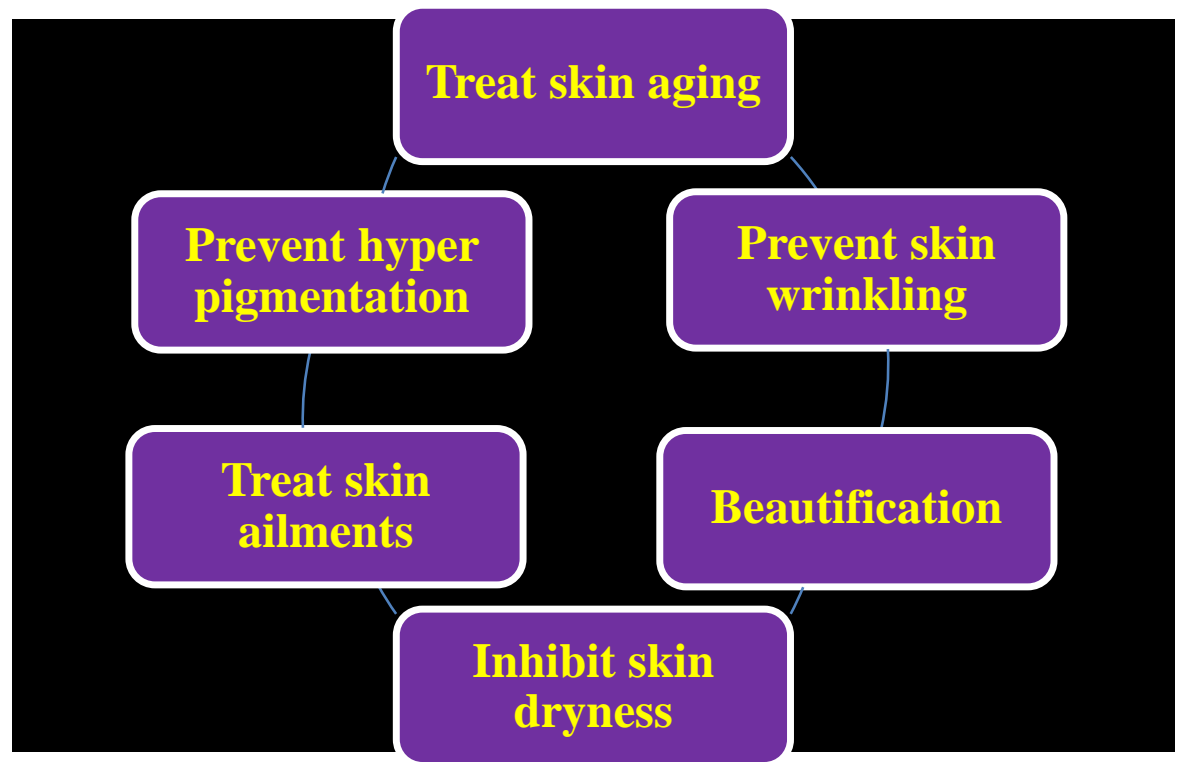

Figure 1. Beneficial effects of herbs/plants as cosmeceuticals

\section{Aloevera}

Aloevera is a plant belonging to liliaceae family and extensively employed for cosmetic purpose. It offers healing effect to skin wound; having moisturizes and softening potential towards skin. The amino acids present in Aloe vera like; leucine \& isoleucine, glycosides saponin possessing cleansing action while other ingredient such as vitamins and folic acid provides antioxidant activity thus delayed symptoms of early ageing. Antimicrobial and moisturizing effect of Aloevera help skin to remain free from microbial deterioration and prevent skin to become dry and rough. Shooting effect of Aloevera provides cooling sensation and prevents initial manifestation of sun burn.

\section{Henna}

Henna comes from Lythraceae family and mainly employed as dye in cosmetic industry in the form of powder or paste. It is employed extensively as coloring dye and as per Indian tradition its use considered as sign of prosperity during festive or marriage season. Many hair care products containing Henna since it's significantly improves hair pigmentation and hides symptoms of ageing.

\section{Neem}

Neem belongs to the family Meliaceae, offers antimicrobial and moisturizing effects therefore present in many cosmetic products used for external application. Soap containing Neem used to manage minor skin infection or as prophylactic agent to prevent fungal infection. Face wash having neem as chief ingredient possessing anti-acne, anti-wrinkles, anti-ageing and anti-microbial effects, it also offers moisturizing and help to reduces pimples.

\section{Turmeric}

Turmeric is a yellow-to-orange powder obtained from herb named Curcuma longa belongs to family Zingiberaceae. Turmeric contains phytochemicals such as; demethoxycurcumin, curcumol, eugenol, curcumin and turmeronols. Curcumin is responsible for yellow color and having many cosmetic values. Turmeric offers antiseptic effects therefore employed to cure small cuts of skin, it possesses antioxidant potential therefore help to scavenge free radicals and delayed symptoms of ageing. Turmeric believes improve complexation therefore many fairness cream containing turmeric as chief ingredient. Turmeric also offers anti-microbial properties therefore help to manage skin infection when applied topically. Its continuous use improves skin texture and colour therefore employed traditionally during the time of marriage. Turmeric present in majority of cosmeceuticals due to its immense cosmetic value. 


\section{Coconut oil}

Coconut oil contains glycerides derived from the fruit or seed of the coconut tree Cocos nucifera, family Arecaceae. Coconut oil is used in cosmetic industry as skin moisturizer and softener to prevent dryness of skin especially in winter season. Coconut oil nourishes hair, maintain hair pigmentation and strengthen hair root. It enhances muscle tone and relaxes muscles therefore also utilized for massage purpose. Other than cosmetic value it is also employed for cooking purpose.

\section{Sunflower oil}

Sunflower oil is non-volatile oil obtained from seeds of Helianthus annuus, family Asteraceae. Sunflower oil contains tocopherols, carotenoids and waxes therefore offer beneficial effects for skin maintenance. It has smoothing properties and many face and body products containing sunflower oil used extensively for cooling and moisturizing effects. It help to nourishes skin and improves complexation.

\section{Jojoba oil}

Jojoba oil extracted from the seeds of desert shrub simmondsia chinenesis, family simmondsiaceae. Jojoba oil help to remove bad odor, color and is stable therefore used in cosmetics industry as a moisturizer and ingredient of exotic fragrances.

\section{Olive oil}

Olive oil is a fixed oil obtained from the fruits of olea europaea, family oleaceae. The major constituents are tripalmitin, tristearate, monosterate, squalene, $\beta$-sitosterol and tocopherol. It is used as skin and hair conditioner

Table 1 Specific use of medicinal plant in cosmetic industry (6-10)

\begin{tabular}{|clll|}
\hline S. No. & Name of plant/herb & \multicolumn{1}{c|}{ Use } & \multicolumn{1}{c|}{ Benefits } \\
\hline $\mathbf{1}$ & $\begin{array}{l}\text { Centella } \\
\text { asiatica }(\text { Gotu-Kola })\end{array}$ & Vayasthapana & $\begin{array}{l}\text { Anti-aging property, } \\
\text { keeping doshas in balance, enhance } \\
\text { collagen synthesis, manage skin } \\
\text { texture }\end{array}$ \\
\hline $\mathbf{2}$ & $\begin{array}{l}\text { Sandalwood } \text { and } \\
\text { vetiver }\end{array}$ & $\begin{array}{l}\text { Varnya/Youthful } \\
\text { Radiance }\end{array}$ & $\begin{array}{l}\text { Enhance bright complexion of the } \\
\text { skin }\end{array}$ \\
\hline $\mathbf{3}$ & $\begin{array}{l}\text { Silk Cotton Tree, } \\
\text { Costus, Grapefruit }\end{array}$ & $\begin{array}{l}\text { Enhancing and nurturing } \\
\text { skin/Tvachya }\end{array}$ & $\begin{array}{l}\text { Maintain moisture balance, } \\
\text { Nourishment to the skin }\end{array}$ \\
\hline $\mathbf{4}$ & Indian sarsaparilla & Enhance glow & $\begin{array}{l}\text { Improve glow by modifying texture } \\
\text { and complaxation }\end{array}$ \\
\hline
\end{tabular}

in the form of lotions \& shampoos. It also employed in cooking industry.

\section{Amla}

Amla is a fruit of tree Emblica Officinalis containing high amount of vitamin $\mathrm{C}$ and oil. Amla used as in the treatment of hair and scalp problems. It is also used in hair loss and for the management of skin ailments in children.

\section{Shikakai}

Shikakai is Acacia concinna Linn. an medicinal plant found in southern Asia. The fruits of plant used for hair cleansing purpose, it is also employed to enhance growth of hair and presence of saponins make this plant very good cleansing agent. Many commercial shampoos available for hair nourishment purpose containing Shikakai as chief constituent.

\section{Rose oil}

Rose oil obtained from Rosa plant and rose water available commercially having many therapeutic benefits. Rose oil used in perfume industry due to its pleasant odour, it boost muscle tone and skin texture, help to clean eye and maintain skin health when applied topically.

\section{Eucalyptus oil}

Eucalyptus oil produced by steam distillation from the plant of Eucalyptus species, this oil used in the preparation of liniments, ointments, toothpaste and in preparation of pharmaceutical flavors. It is essential oil therefore used for its pleasant odour and as cosmetic purpose exclusively employed in dentifrices/ toothpaste. 


\section{Acknowledgement}

The authors are thankful to IJIST Journal for publishing their article.

\section{Conflicts of Interest}

The author declares that there are no conflicts of interest.

\section{References}

1. Joshi H (2012) Potentials of traditional medicinal chemistry in cosmetology industry; prospectives and perspectives. Anaplastology an open access journal 1: 3.

2. Sahu AN, Jha S, Dubey SD (2011) Formulation \& Evaluation of curcuminoid based herbal face cream. Indo-Global Journal of Pharmaceutical Sciences 1: 7784.

3. Pandey S, Meshya N, Viral D (2010) Herbs play an important role in the field of cosmetics. International Journal of Pharm Tech Research 2: 632-639.
4. Gediya SK, Mistry RB, Patel UK, Blessy M, Jain HN (2011) Herbal plants : used as cosmetics. J Nat Prod Plant Resour 1: 24-32.

5. Sharma HD, Paramesh R (2010) Trends in aging and skin care: Ayurvedic concepts. Journal of Ayurveda and Integrative Medicine 1: 110-113.

6. Kadam VS, Chintale AG, Deshmukh KP, Nalwad DN (2013) Cosmeceuticals an emerging concept: A comprehensive Review. International journal of research in pharmacy and chemistry $3: 308-316$.

7. Ligade VS, Udupa N (2010) Pharmaceuticals, Cosmeceuticals and Nutraceuticals: An Overview of Regulations (1stedn.) Career Publications.

8. Mukul, S.; Surabhi, K.; Atul, N. Cosmeceuticals for the skin: An overview. Asian J. Pharm. Clin. Res. 2011, 4, 1-6.

9. Fowler, J.F., Jr.; Woolery-Loyd, H.; Waldorf, H.; Saini, R. Innovations in natural ingredients and their use in skin care. J. Drugs Dermatol. 2010, 9, 72-81.

10. Dureja, H.; Kaushik, D.; Gupta, M.; Kumar, V.; Lather, V. Cosmeceuticals: An emerging concept. Indian J. Pharm. 2005, 37, 155-159. 